\title{
Sociology of individual tragedies. Homicides and suicides: Cross-country cluster analysis
}

\author{
Leonid Grigoryev $^{\mathrm{a}, \mathrm{b},{ }^{*}, \text { Lyubov Popovets }}{ }^{\mathrm{a}}$ \\ a HSE University, Moscow, Russian Federation \\ ${ }^{\mathrm{b}}$ Analytical Centre for the Government of Russian Federation, Moscow, Russian Federation
}

\begin{abstract}
Sociology and psychology closely study the phenomena of homicide and suicide among countries of the world, but both remain little studied in the context of the levels of countries' development and international comparisons. Developed countries (in terms of GDP per capita) show a decrease in the relative rate of homicides, but the case of suicides is not so explicit. This paper examines the relative levels of suicides and homicides all around the world in the context of socio-economic indices as well as indicators of mental health among the population. Addressing the example of the BRICS countries, the authors discuss the impact of economic imbalances on homicide and suicide levels. The analysis demonstrates that social inequality determines cross-country differences for relative levels in terms of homicide rates, including the course of events in the postSoviet countries. And in the case of Russia, it is possible to make a conclusion not only about the presence of deep inter-regional differences, but also about a large-scale reduction in the frequency of two tragic phenomena between 2000 and 2017 during the economic recovery.
\end{abstract}

Keywords: homicides, suicides, sociology, inequality, Russia, transformation, BRICS. JEL classification: D63, N30, O57, P20.

\section{Introduction. The eternal evil of the individual tragedies: formulating the problem}

Human progress is never on a continuous upward trajectory, and, even in many economically and socially stable countries, people experience psychological stresses and various personal and social problems. Throughout history, wars,

\footnotetext{
* Corresponding author, E-mail address: 1grigor1@yandex.ru
} 
epidemics, and crime - both on an individual and mass scale — all of them resulted in losses of human lives. We are not writing the history of crime, but we believe it's important to understand that lethal interpersonal violence, as well as suicides, cause a massive annual loss of life without any particular military or social upheaval. The nature of homicide and suicide derives from individual behavior in countries with different cultural codes (Sherman et al., 2014), levels of development, and social conditions (Smith and Zahn, 1999). Every tragic event of either kind is an individual tragedy. Their nature has both psychological and social roots, and this is the reason for the great diversity of country models of tragedies in this research. In our opinion, the scientific world is somewhat hesitant to face the problem, partly because of the fear of opening Pandora's Box. Therefore we have focused on the general social characteristics of these dramatic phenomena, or, more precisely, these individual tragedies under current conditions in order to help find approaches towards reducing their absolute numbers and relative rates.

The transition to sustainable development in any country requires solutions to problems which societies are facing at different developmental stages. These stages, apparently, require individual approaches to those problems. Most countries signed the UN Sustainable Development Goals (SDG) Agreement, which describes mankind's big-picture problems and the tasks aimed at solving them. However, the SDG fails to focus on the acute tragic phenomena of homicides and suicides as social problems. Societal tensions heavily impact individuals, and homicides and suicides represent an extreme degree of that tension. They are quite conspicuous in the life of a society, are displayed by the mass media and mentioned in fictional literature and cinema. However, they remain outside the focus of social studies, and are seen more as an inevitable evil of mental health than as a social problem for a given historical period. We take them as indicators of a society's lack of well-being along with crime as a whole, or as a result of desperation in the context of perceived personal failures.

Contemporary science is looking for correlations between socially induced life events and how a society's characteristics (culture, political system, etc.) determine people's status. However, in our opinion, cultural codes are mostly connected to social characteristics that are determined by the historic process. Social disorders are one of the tragic but persistent characteristics of a given country's social life. By this we mean individuals committing violence against themselves or other people, namely homicide and suicide.

We believe that improved social analysis of the condition and development of countries by using the indicators of the relative level (per 100,000 people) of the mentioned events could provide an opportunity to measure a society's developmental level and "stability." The UN's 2015 Sustainable Development Goals (Goal 3.4) state the need to reduce infectious diseases and improve mental health, using the suicide rate as one of the indicators. In our opinion, this is not enough. The UN SDGs say nothing about reducing the rates of homicide and suicide as hazardous social phenomena, whereas they should have proposed at least reducing them along with the goals for reducing extreme poverty, disease, and overall mortality (UN, 2015).

We intend to demonstrate that these two tragic phenomena in the life of a society not only have their own particular psychological explanations, but are also 
to some extent dependent on socioeconomic processes. We believe that the rate at which life is lost can be studied within the framework of the existing, longstanding tradition. However, we will review several social hypotheses regarding the values of these indicators across 157 countries with populations exceeding 2 million each in 2016. Our focus will be on:

- how persistent a country's rates (frequency) of homicide and suicide are during the $21^{\text {st }}$ century;

- how these indicators change across countries with the growth of GDP per capita, depending on their stage of development;

- what social and psychological factors influence these indicators;

- to what degree the measurement of "happiness" can be viewed as something running counter to suicidal motives in a society, with a particular review of conditions in the BRICS countries;

- the current situation with respect to these phenomena in transitional economies during transformation processes, particularly in Russia during the $21^{\text {st }}$ century, and based upon the country's types of regions.

In other words, our aim is as follows: to identify the basic (stylized) facts about the factors which affect homicide and suicide rates in a society, reflecting elements of anomie in some societies. The term "anomie" is used in this paper in the context given by Emile Durkheim: a state of disintegration and mismatch between the values and goals of social classes (Durkheim, 1994). The theory of homicide and suicide was elaborated in the works of Andrew Henry and James Short and a number of other authors. The majority of the works draw a parallel between homicide and individual aggression, social disorganization, violence in society, and poverty; however, their evidence is based mostly on sociological indicators in the United States.

An important research of the 1990s (Unnithan et al., 1994) cites the results of studies demonstrating that homicide and suicide are caused by common factors and are strongly correlated, while the suicide-to-homicide ratio is constant within a given area. In the comparatively recent review of theories related to homicide, Jay Corzine emphasized the role of social and cultural factors: "In the final contribution to this special issue, Thomas evaluates the role of social disorganization, cultural, and strain theories in developing an understanding of the findings from the recent renewal of interest in the impact of immigration on crime, including homicide" (Corzine, 2011, p. 317). Thus, theories associated with the phenomenon of homicide proper cover a wide range of topics, but we did not find explicit references to stages of socioeconomic development.

Suicide - both as a psychological and social phenomenon, in particular correlating with homicide - has been studied mostly by American and Western European (Norway, Sweden) scientists. These studies contain a certain (mostly on the mental side) research framework paradigm and a sample of statistical data.

Economic factors were becoming a part of the discourse from time to time. For example, the pioneer researchers in this field, Henry and Short (1954), analyzed the correlation between business cycles and homicide and suicide rates based on a data sample from the United States population. They tested a hypothesis that economic factors often cause frustration in individuals, which triggers aggressive reactions directed at surrounding people or towards oneself, which affects the rates of homicide and suicide. Researchers found a positive correlation be- 
tween homicide and low social status, a negative correlation between suicide and the strength of social connections, but a positive relationship between homicide and the strength of social connections. That means that low living standards do not mean a high suicide rate, because a person's aggression and dissatisfaction are directed at external living conditions or objects. On the other hand, in a favorable social environment, individuals are more inclined to blame themselves, leading to auto-aggression and depression.

In 1986 David Lester from Stockton University carried out a research of suicide and homicide rates and living standards, based on Henry and Short's theory. In that study, Lester (1986) supported the idea that suicide rates are correlated with income levels, alcoholism, and "professionalism," i.e. the risk group consists of people with higher income, social status, and alcoholism. Homicide rates are also correlated with alcohol addiction and "professionalism," income, the urbanization and industrialization level, and population heterogeneity.

In a body of studies on the correlation between suicide rates and socioeconomic factors, Bijou Yang's is one of the most comprehensive. In his The Economy and suicide: A time-series study of the United States, Yang (1992) suggested that the economy and the proportion of women in the workforce may have a direct and multi-pronged effect on suicide rates: unemployment and divorce rates may increase them, while Catholicism may reduce them. He tested his hypotheses across various population groups. According to Yang, neither economic growth nor recessions made suicide rates increase or decrease; unemployment, particularly among women, did not have a strong impact on suicide rates, but divorce, by contrast, did.

Moving from social disorder indicators to the intuitively opposite one, i.e. the level of happiness, we should mention the theory of Richard Easterlin, who studied the level of social inequality as connected to per capita income. Easterlin (1995) found that the level of happiness depends rather on relative, than absolute level of income. This is because individuals, when measuring their well-being, tend to compare it to that of people around them. Alan Collins came to similar conclusions and specified that suicide rates were higher after economic crisis than during its most severe periods (Collins et al., 2019). Accordingly, we may assume that growing social inequality makes the level of happiness fall in a given society. The growing welfare of the small part of population might fall upon relative reduction in the well-being of its much greater part.

\section{General trends in the world}

Statistical analysis of homicide and suicide indicators is a relatively recent course of research (see review in Unnithan et al., 1994, p. 51-52). In particular, in 1992, Prabha Unnithan and Hugh Whitt came to the conclusion that it is the level of inequality, rather than economic development, which affects the level of lethal violence or homicide, although the relationship is not linear. However, the correlation is proportional: inequality increases the homicide rate and the correlation between homicide and economic development is inversely proportional (Unnithan and Whitt, 1992, p. 52).

We should also mention the review by David Lester (1986). He calculated pair correlations between homicide and suicide rates and the standard of living across 
43 countries, and compared his results with ones of Henry and Short (1954). The standard of living was found to have a positive $(0.455)$ correlation with suicide, but a negative $(-0.650)$ correlation with homicide. These results might be disappointing for those who believe in the linear progress of mankind, since suicide rates grow along with per capita income across the world. Thus, the idea of the importance of inequality to homicide rates is well-known. Nevertheless, questions arise: why is this so and how general is it? What happened 30 years after the series of studies in the 1970s?

We intend to analyze the current situation; that is why we use 2016 data for 157 countries, ascribed to seven clusters. They can be viewed as information on social stratification (keeping all possible limitations in mind): first, as the cluster structure based on each country's level of development and second as social (decile) structure within individual countries. We rely on the cluster approach to international inequality, as elaborated upon in a number of works (see Grigoryev and Pavlyushina, 2018a, 2018b). The authors identified seven clusters of countries with differing levels of per capita income, employment rates, energy consumption, and economic development. The authors assume that increasing absolute well-being across the world does not reduce relative social inequality, which is one of the reasons behind social problems and conflicts that arise even when the overall well-being of the population is growing. On the basic hypothesis of our study, we assigned all countries in specific clusters based on differences in GDP (PPP) per capita (Grigoryev and Pavlyushina, 2018b).

We assigned countries in which Islam is the state religion in a separate group (21 countries), as it has a substantial effect on socioeconomic and cultural conditions. In particular, laws of religion, such as the ban on alcohol, are controlled at the state level. The specifics of cultural codes for Muslim countries and their sociopolitical institutions enable us to examine them separately within the framework of our topic.

We selected the following indicators for statistical analysis: mental disorder rate; depression rate; alcohol/drug addiction rate; unemployment rate; GDP (PPP) per capita; calculated "happiness" index; homicide and suicide rates.

The rate of homicide, or mortality caused by interpersonal violence, reflects not only the nature of social connections, but also law enforcement control conditions within the country. We consider this rate to be high in societies undergoing socioeconomic transformation, during which the state's ability to regulate social relations is reduced (case of anomie). However, these states are not necessarily the poorest. The hypothesis regarding suicide rates is that their high rates may be associated with economic development and reflect personal problems within a social context (bankruptcies, career failure).

We also used the "happiness" indicator (see Helliwell et al., 2016), which reflects a kind of an expert estimate of the quality of social life and institutions. It is heavily dependent on the GDP per capita (logarithmic) within a given country (see more in Section 5). This index became quite common in the research while it does not reflect the subjective opinions of the citizens of any country. We would like to double check whether it actually influences the key subjects of our study.

Table 1 contains the average values for the indicators used across 157 countries divided into 7 clusters in 2016. 
Table 1

Average indices across the 7 clusters, 2016 (157 countries, simple means, rounded).

\begin{tabular}{|c|c|c|c|c|c|c|c|c|c|c|}
\hline 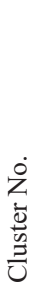 & 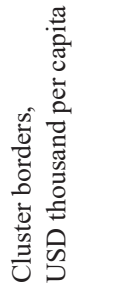 & 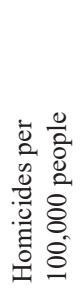 &  & 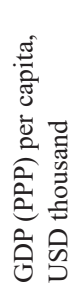 & 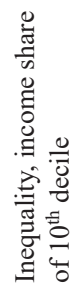 & 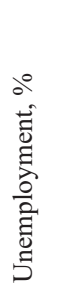 &  & 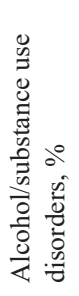 & 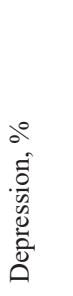 & 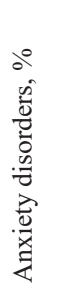 \\
\hline 1 & $>35.1$ & 1.25 & 14.03 & 53.7 & 24.79 & 6.11 & 7.04 & 2.99 & 4.24 & 5.60 \\
\hline 2 & $21.1-35.0$ & 5.19 & 14.84 & 30.8 & 27.42 & 8.21 & 6.00 & 2.83 & 3.76 & 4.16 \\
\hline 3 & $14.0-21.0$ & 5.77 & 11.88 & 19.5 & $\mathrm{n} / \mathrm{a}$ & 7.47 & 5.70 & 2.64 & 3.69 & 3.92 \\
\hline 4 & $7.0-13.9$ & 13.39 & 9.02 & 12.4 & 29.28 & 10.78 & 5.29 & 2.56 & 3.30 & 3.59 \\
\hline 5 & $3.2-6.9$ & 5.95 & 7.88 & 5.5 & 31.04 & 4.98 & 4.90 & 2.07 & 3.67 & 3.39 \\
\hline 6 & $1.8-3.1$ & 7.89 & 7.19 & 3.0 & 32.26 & 7.31 & 4.26 & 1.91 & 3.93 & 3.30 \\
\hline 7 & $<1.8$ & 6.21 & 7.40 & 1.5 & 33.24 & 6.40 & 4.02 & 1.91 & 4.25 & 3.37 \\
\hline
\end{tabular}

Note: $\mathrm{n} / \mathrm{a}$ - data not available.

Sources: World Bank; World Health Organization; Institute for Health Metrics and Evaluation; Grigoryev and Pavluyshina (2018a).

In order to assure that the indicators are stable over time, and to rule out the possibility of a random distribution of their values, we calculated the correlation coefficient between homicide rates in 2000 and in 2016, and for suicide rates in the same years. The correlation between homicide rates in 2000 and 2016 across the 157 countries is 0.93 ; the same calculation for suicide rates is 0.90 . It reveals that the change in homicide and suicide rates for both years is also relatively low. As shown in section 6 below, most of these changes are specific to transitional economies. Thus, we consider that conclusions made regarding the main subject of this research should stay correct for the most years or for any of them. Another notable point is that in the "richest" part of the sample (the 1 st cluster of countries), homicide and suicide rates were at nearly the same level in 2000 and in 2016. At the same time, in the $2^{\text {nd }}$ cluster countries (which include many transitional economies) there has been a noticeable reduction in both homicide and suicide rates during the $21^{\text {st }}$ century (details below). In clusters 3 through 7 , there have been no major changes except for a slight reduction in "normal" suicide rates for a few countries.

But at the same time, the suicide rate in some countries of the state Islam countries group was higher in 2016 than in 2000, although the overall rate declined. We will study these countries later on in more detail. Therefore, Fig. 1 shows data on homicide and suicide rates across 136 countries in 2016 (i.e. excluding countries with the state religion-Islam), sorted out in ascending order by GDP (PPP) per capita.

Homicide and suicide rates across all countries demonstrate remarkable dynamic. The most significant facts are simple, as shown in Table 1: peak homicide rates can be observed in cluster 4 , then they decline and dramatically drop in cluster 1. Actually that means that a high level of income and a stable legal framework ensure low homicide rates in cluster 1, although the level of inequality remains quite high. Nonetheless, the suicide rate rises despite increasing wellbeing, reaching its highs in clusters 1 and 2 . 
Homicides






\section{Correlation and regression analysis}

To build regression models, we took anxiety disorders' rate, depression rate, alcohol/substance use disorders rate, GDP (PPP) per capita growth rate, unemployment rate, and inequality level in percent and GDP (PPP) per capita (international dollars). All indicators are those of 2016. To test our hypotheses, we analyzed suicide and homicide rates separately based on data from 157 countries for 2016.

Equations for: homicides, suicides; in all equations $N=136$ (without 21 countries with the state Islamic religion); year $=2016$. Variables:

- $g d p$ - GDP (PPP) per capita;

- unemp - unemployment, \%;

- ineq - inequality, income share of $10^{\text {th }}$ decile;

- alcohol-alcohol and substance use disorders;

- depr-depression;

- anxiety - anxiety disorders ${ }^{1}$;

- happ - happiness score/satisfaction.

The analysis of homicide rates is presented below. We calculated the correlation ratios and composed equations across the entire sample (Table 2).

This correlation table is brief but quite clear. Homicide frequency is negatively correlated with GDP per capita, anxiety disorders and depression and does not correlate with suicide frequency. A positive correlation with the happiness index is evident, as the latter is composed by the GDP per capita logarithm. Inequality, unemployment, and alcohol/substance use disorders create the "positive side" of the correlations, so to speak.

The regression equation $\mathrm{H}-1$ (Table 3 ) for the homicide rate across countries has a predictably low determination coefficient and only two independent variables: inequality and anxiety disorders (GDP per capita correlates with inequality).

Table 2

Correlation between homicide rates and selected indicators across 136 countries, 2016.

\begin{tabular}{lc}
\hline & Homicides per 100,000 people \\
\hline Suicides per 100,000 people & -0.04 \\
GDP (PPP) per capita, \$ & 0.21 \\
Inequality, \% & 0.43 \\
Unemployment, \% & 0.16 \\
Happiness index, points & 0.09 \\
Alcohol/substance use disorders, \% & 0.13 \\
Depression, \% & -0.09 \\
Anxiety disorders, \% & -0.18 \\
\hline
\end{tabular}

Source: Authors' calculations.

Table 3

Equation H-1: Homicides (136 countries).

\begin{tabular}{lllll}
\hline & Const & ineq & anxiety & $R^{2}$ \\
\hline Regression coefficients & -5.77 & 0.6 & -1.5 & 0.22 \\
$t$-statistics & & 3.73 & -1.955 & \\
\hline
\end{tabular}

Source: Authors' calculations.

\footnotetext{
1 According to the classification by the National Alliance on Mental Illness. "Anxiety disorder" includes: general anxiety disorder, social anxiety disorder, panic attacks, phobias, etc.
} 
The conclusion from our preliminary analysis for all countries is quite consistent with earlier scientific findings (Lester): inequality is the most significant issue across the entire history of homicide studies, and below we will examine this correlation by clusters.

The suicide rate is a completely different story and far less explicable through social factors (at a glance). Table 4 gives an idea about the influences of a number of factors on this rate): alcohol/substance use disorders are the most important, followed by depression and the GDP level. Correlation with inequality is negative. From a psychological (mental health) perspective the observed effects of depression and alcohol are quite clear.

We should note the positive correlation between suicide frequency and both GDP (equation S-2; Table 5) and "happiness", and this draws attention to two things: strong correlation between "happiness" indicators and GDP per capita and, accordingly, the limited practical usefulness of the "happiness" indicator as an opposite to suicide, depression and various societal disorders. After removing multicollinearity, a simple regression equation remains: alcohol/substance use disorders, and depression. At the first glance, both indicators are of a psychological rather than social nature. However, they grow significantly as GDP per capita grows, and act as proxies for all social dramas in a developed capitalist society. We should note that this trend was persistent in 2016, but had been previously observed.

So far we leave one equation that provides the best results: alcoholism/drug addiction and depression. Although at first glance this result seems to be pointing "back" towards psychology, we believe that the social studies and literature (including fiction) cover the growing phenomena of depression and alcoholism in a complex structure of modern society. And many individuals struggle to escape from loneliness and depression and become vulnerable and highly emotional over personal, business, and psychological disasters. These two determinants of suicide rates in the equations could be considered as closely connected to the social life background in developed economies.

Table 4

Correlation of suicide rates across 136 countries, 2016.

\begin{tabular}{lc}
\hline & Suicides per 100,000 people \\
\hline Homicides per 100,000 people & -0.04 \\
GDP (PPP) per capita, \$ & 0.42 \\
Inequality, \% & -0.37 \\
Unemployment, \% & -0.03 \\
"Happiness" index, points & 0.33 \\
Alcohol/substance use disorders, \% & 0.60 \\
Depression, \% & 0.23 \\
Anxiety disorders, \% & 0.14 \\
\hline
\end{tabular}

Source: Authors' calculations.

Table 5

Equation S-2: Suicides (136 countries).

\begin{tabular}{lllll}
\hline & Const & alcohol & depr & $R^{2}$ \\
\hline Regression coefficients & -4.88 & 3.7 & 1.63 & 0.395 \\
$t$-statistics & & 8.57 & 2.8 & \\
\hline
\end{tabular}

Source: Authors' calculations. 
Below we carry out more detailed analysis of "normal" homicide and suicide rates based on a country's level of development, assuming that this will either support the general results and thereby enhance their significance, or produce further considerations for elaborations on the topic.

\section{Analysis of homicide rates across country clusters}

To identify the specific characteristics of homicide and suicide rates, we examine these indicators in more details by country groups (Table 6).

The homicide rate index is correlated rather highly with the inequality index for the 136 countries, and for all three calculated equations by groups. For the most developed countries (clusters 1-2, equation H-3; Table 7) the rate closely correlates with anxiety disorders $(-0.43)$, with GDP (PPP) per capita $(-0.37)$ and inequality (0.41). Inequality and GDP (PPP) per capita are correlated by -0.33 , which is why we included the inequality indicator in the equation with adding alcohol/substance use disorders.

The homicide rate is higher in countries not just with low GDP (PPP) per capita, but in post-Soviet and Latin American countries (Latvia, Kazakhstan, Romania, Russia, Chile, Columbia, Salvador), which are characterized by a higher level of social disintegration while social institutions are less effective than in the developed Western European countries or, alternatively, in traditional societies.

Homicide rates index in clusters 3-4 (equation H-4; Table 8) correlates positively with the inequality level (0.5) and "happiness" (0.29), and negatively with GDP (PPP) per capita (-0.39). Actually only inequality matters in this case also, but we left variables of "happiness" and GDP per capita to demonstrate the absence of the alternative.

Table 6

Correlation of homicide rates by cluster groups.

\begin{tabular}{|c|c|c|c|c|c|c|c|c|}
\hline & 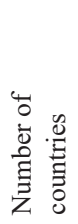 & 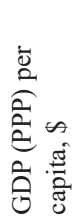 & 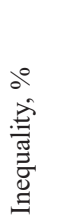 &  & 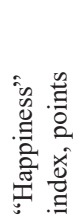 & 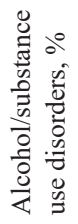 &  &  \\
\hline Clusters 1-2 & 43 & -0.37 & 0.41 & -0.09 & -0.14 & 0.29 & -0.14 & -0.43 \\
\hline Clusters 3-4 & 35 & -0.39 & 0.50 & -0.04 & 0.29 & 0.15 & 0.09 & -0.01 \\
\hline Clusters 5-7 & 58 & 0.15 & 0.45 & 0.39 & 0.4 & 0.22 & 0.01 & -0.01 \\
\hline Islamic & 21 & -0.33 & n.a. ${ }^{\text {a) }}$ & 0.04 & -0.55 & 0.48 & 0.13 & -0.10 \\
\hline
\end{tabular}

a) Data available for only 4 out of 21 countries. Source: Authors' calculations.

Table 7

Equation H-3: Homicides (1-2 clusters).

\begin{tabular}{llllll}
\hline & Const & ineq & alcohol & anxiety & $R^{2}$ \\
\hline Regression coefficients & -9.1 & 0.64 & 0.17 & -1.63 & 0.45 \\
$t$-statistics & & 3.75 & 0.57 & -1.88 & \\
\hline
\end{tabular}

Source: Authors' calculations. 
Table 8

Equation H-4: Homicides (3-4 clusters).

\begin{tabular}{lllll}
\hline & Const & $g d p$ & happ & $R^{2}$ \\
\hline Regression coefficients & 0.97 & -0.001 & 5.80 & 0.32 \\
$t$-statistics & & -3.3 & 2.75 & \\
\hline
\end{tabular}

Source: Authors' calculations.

Table 9

Equation H-5: Homicides (5-7 clusters).

\begin{tabular}{lllll}
\hline & Const & unemp & alcohol & $R^{2}$ \\
\hline Regression coefficients & -4.56 & 0.58 & 2.86 & 0.3 \\
$t$-statistics & & 3.53 & 1.7 & \\
\hline
\end{tabular}

Source: Authors' calculations.

Table 10

Equation H-6: Homicides (Islamic countries).

\begin{tabular}{lllll}
\hline & Const & alcohol & happ & $R^{2}$ \\
\hline Regression coefficients & 5 & 6.33 & -2.28 & 0.465 \\
$t$-statistics & & 2.20 & -2.73 & \\
\hline
\end{tabular}

Source: Authors' calculations.

The highest homicide rates are found in Latin American countries (Colombia, Salvador, Guatemala) and South Africa. The lowest homicide rates are found in China, Croatia and Indonesia.

In clusters 5-7 (less developed countries - below 6,500 international dollars per capita), homicide rates still correlate (equation H-5; Table 9) most closely with the inequality level $(0.45)$. These countries demonstrate positive correlation not only with alcohol/substance use disorders $(0.22)$ but with unemployment (0.4).

The unemployment in clusters 5-7 significantly increases the homicide rateso we included it in the equation (inequality left out to avoid multicollinearity). The homicide rate varies noticeably: in Venezuela, Lesotho, and Honduras it is considerably higher than in other countries within the group, particularly over 30 times higher than in Burundi, Laos, and Burkina Faso.

The analysis of the Islamic cluster (21 countries - equation H-6; Table 10) shows that the homicide rate is pegged to the level of alcohol/substance use disorders (correlation +0.48$)$ and "happiness" $(-0.55)$, which is correlated with GDP per capita at 0.67 within this group. There are insufficient data on inequality (the decile coefficient was only calculated for 4 countries), and we kept only "happiness" and alcohol/substance use disorders.

Maximum values prevail mostly in poor countries - Afghanistan and Iraq, while the lowest homicide rates are in Egypt, Oman, and Saudi Arabia.

Overall, the analysis across the clusters (levels of development) showed a highly persistent correlation between homicide frequency and inequality. This verifies the analyses in previous studies based on data from developed countries. Thus, this fact can be extrapolated to the $21^{\text {st }}$ century and to developing countries. However, the mechanism for this correlation may become the subject of research: 
a single mechanism may represent multiple mechanisms until this possibility is not eliminated by analytical means.

\section{Analysis of suicide rates across clusters}

The development level has its own role: the role of alcohol/drug addiction increases as the level of development does. The role of depression is especially prominent in clusters 3-4 (transition economies), although inequality negatively correlates with suicide, unlike homicide. We shall also emphasize that "indifference" of the "happiness" indicator to suicide rate (there is a positive correlation in the poorest country group though) might be attributed to the growth rates. Table 11 shows significant differences in relationships by country groups.

For the overall suicide rate (equation S-7; Table 12) in clusters 1-2, significant correlations included alcohol/substance use disorders (0.6), the homicide rate (0.26), anxiety disorders $(-0.4)$, unemployment $(-0.3)$, and inequality $(-0.3)$. Through further calculations, taking into account the minimization of multicollinearity, we obtained the following.

The constant term in the equation is 14.48 , i.e. in the full absence of unemployment, alcohol, drug, and anxiety disorders, the suicide rate would be quite high. This means that, in general, it is difficult to explain the variation of this variable through basic social, psychological and economic indicators. The very phenomenon may be the result of complex psychic processes, a reaction to the perception of oneself in a social context as something that has no sense (see Van Orden et al., 2010). However, the high significance of the variable $x 4$, i.e. alcohol/substance use disorders, was confirmed in previous studies on the nature of suicide (see Hufford, 2001).

Table 11

Correlation of suicide rates by the cluster groups.

\begin{tabular}{|c|c|c|c|c|c|c|c|c|c|}
\hline & 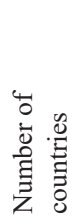 &  & 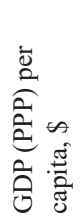 & 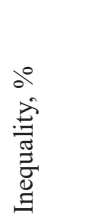 & 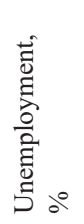 & 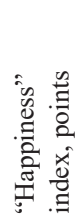 & 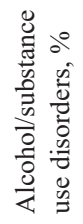 &  & 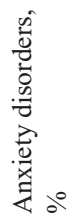 \\
\hline Clusters 1-2 & 43 & 0.26 & -0.12 & -0.30 & -0.29 & -0.18 & 0.59 & 0.11 & -0.39 \\
\hline Clusters 3-4 & 35 & -0.07 & 0.23 & -0.49 & -0.05 & -0.09 & 0.49 & 0.51 & 0.06 \\
\hline Clusters 5-7 & 58 & 0.08 & 0.05 & 0.12 & 0.07 & 0.27 & 0.32 & 0.25 & 0.04 \\
\hline Islamic & 21 & 0.08 & 0.09 & n. a. ${ }^{\text {a) }}$ & 0.05 & -0.17 & 0.21 & 0.06 & -0.12 \\
\hline
\end{tabular}

a) Data are available for only 4 out of 21 countries. Source: Authors' calculations.

Table 12

Equation S-7: Suicides (136 countries).

\begin{tabular}{llllll}
\hline & Const & unemp & alcohol & anxiety & $R^{2}$ \\
\hline Regression coefficients & 14.48 & -0.24 & 2.90 & -1.40 & 0.465 \\
$t$-statistics & & -1.29 & 4.27 & -2.34 & \\
\hline
\end{tabular}

Source: Authors' calculations. 
The peak values were found in the Baltic states: Lithuania, Estonia, Latvia, as well as in Russia and the United States. Thus, the suicide rate in Russia is twice as high as the group average. The lowest values, by contrast, are characteristic of Mediterranean countries: Italy, Greece, Spain, and Cyprus, as well as Israel, Turkey, and Panama.

The suicide rates (equation S-8; Table 13) in clusters 3-4 were most influenced by the level of alcohol/substance use disorders (correlation 0.5 ), depression $(0.51)$, and inequality $(-0.5)$, whereas no correlation was found between depression and suicide. Since these indicators often have multi-correlations, we chose only one equation with the predictors of alcohol/substance use disorders and GDP (PPP) per capita.

The data indicates increased suicide rates in Belarus and Ukraine. Rates for Serbia and Uruguay were lower than in these countries, but higher than the group average. In Azerbaijan, Indonesia, and the Philippines, where the Muslim population prevails, the suicide rate is 4 times lower than in Belarus and Ukraine.

The suicide rates (equation S-9; Table 14) in clusters 5-7 are impacted by the level of alcohol/substance use disorders (correlation 0.32), the level of "happiness" (0.27), and depression (0.25). This means that the group containing clusters 5-7 is the only one where the suicide rate is, on the one hand, determined logically, but on the other hand, is a negative function of the level of "happiness."

Accordingly, the highest suicide rates in this group were observed in Moldova, India, and less-developed African countries: Lesotho and Kiribati. Honduras and Jamaica are characterized by low suicide rates. The proportionate change in the suicide rate and the level of "happiness" in this group is related to the fact that alcohol and drug consumption increases the mortality rate caused by suicide, but also increases the level of "happiness" within the group.

The analysis of the Islamic cluster (21 countries) shows that the only relatively significant correlation for the suicide rate in this group $(-0.2)$ is with the level of alcohol/substance use disorders. A verification of the regression coefficients for the suicide rate has demonstrated that all variables are insignificant. The suicide rate is relatively high in poorer Yemen and in economically secure Qatar, and is the lowest within Kuwait as shown on Fig. 2.

Table 13

Equation S-8: Suicides (clusters 3-4).

\begin{tabular}{lllll}
\hline & Const & gdp & alcohol & $R^{2}$ \\
\hline Regression coefficients & -3.24 & 0.035 & 3.1 & 0.315 \\
$t$-statistics & & 1.88 & 3.5 & \\
\hline
\end{tabular}

Source: Authors' calculations.

Table 14

Equation S-9: Suicides (clusters 5-7).

\begin{tabular}{lllll}
\hline & Const & alcohol & depr & $R^{2}$ \\
\hline Regression coefficients & -4.7 & 2.68 & 1.80 & 0.184 \\
$t$-statistics & & 2.83 & 2.35 & \\
\hline
\end{tabular}

Source: Authors' calculations. 


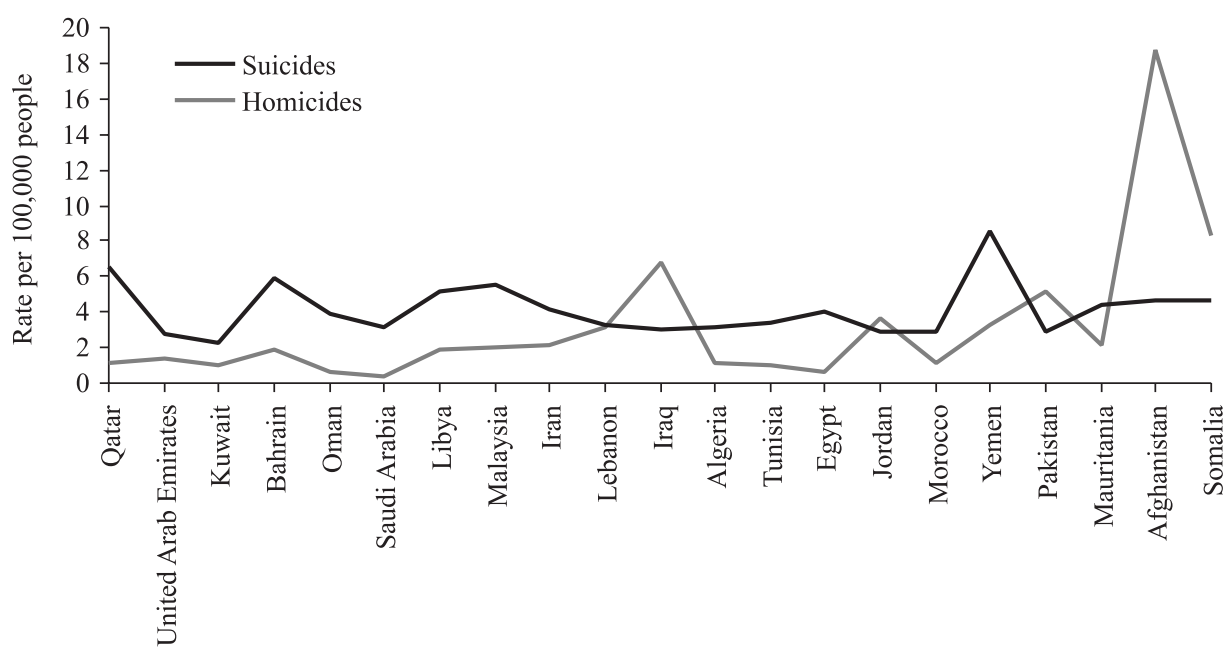

Fig. 2. Suicide and homicide rates per 100,000 people in Muslim countries, 2016.

Sources: World Bank; World Health Organization; Institute for Health Metrics and Evaluation.

An analysis of the character of Muslim society is not a goal of this paper. We would like to state that the facts for most of the world and for the cluster of 21 countries in which Islam is the national religion differ considerably. In this regard, we should note a whole number of specific features. First of all, they include the low homicide and suicide rates in most Muslim countries compared with the other countries under review; the homicide and suicide rates are very close; the factor of growing GDP per capita plays no noticeable role (Table 15). This is an opportunity for experts on Muslim countries to find explanations for these differences.

There are also no significant differences between specific values for the two indicators, as seen in other countries. In this respect, however, we can see an exception to the rule: in Afghanistan, Iraq, and Somalia, violence is rampant due to long-lasting conflicts and a weak (non-existent) centralized power. Another group of three countries can be examined in a similar way: Pakistan, Jordan, and Lebanon, where homicide frequency is close to or exceeds suicide rates. We be-

\begin{tabular}{|c|c|c|c|c|c|c|c|c|c|c|}
\hline 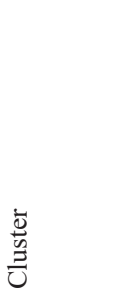 & 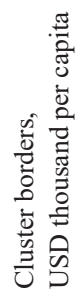 & 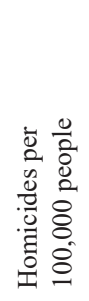 & 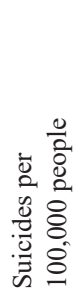 & 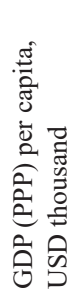 & 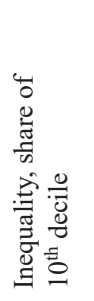 & 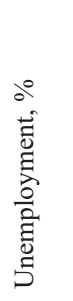 &  & 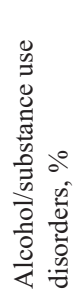 & 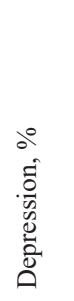 & 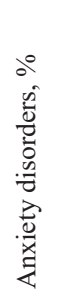 \\
\hline $\begin{array}{l}\text { Islamic } \\
\text { countries }^{\text {a) }}\end{array}$ & - & 1.87 & 4.17 & 31.28 & $28.1^{\mathrm{b})}$ & 8.03 & 5.4 & 1.59 & 4.06 & 4.88 \\
\hline
\end{tabular}

a) 21 Muslim countries were assigned to a separate cluster regardless of their per capita income; all countries are included among the 7 clusters based on their level of income.

b) Data are only available for 4 out of 21 countries.

Source: Authors' calculations. 
lieve that this is caused by their proximity to Afghanistan and Syria, which have been ravaged by armed conflicts.

To yield more precise conclusions regarding the specifics of suicide indicators, we conducted an analysis across gender and age groups with the same predictors. On the whole, the highest suicide rates were observed in post-Soviet countries: Lithuania, Russia, Belarus, Kazakhstan, and Ukraine (32.0, 31.0, 26.2, 22.5, and 22.4 per 100,000 people, respectively, whereas the average across the 136 countries was 10.3), which are also transitional economies undergoing the formation of political and economic institutions amid a severe economic crisis.

Suicide rates usually rise along with the age of the group analyzed. One possible reason is the feeling of loneliness and of one's uselessness, caused, among other things, by "failures" of individuals in the highly competitive social system. This is also one of the characteristics of developing and less developed countries: social failure, i.e. a situation of ineffectiveness or inconsistency of the social status and competencies of certain individuals, where opportunities for other individuals are severely limited (Boskoff, 1982).

Among people aged 50 to 69 , the greatest suicide rates were registered in Lesotho (67.84 per 100,000), Lithuania (53.24), Zimbabwe (52.4), Russia (41.5), and South Korea (41.5), while the overall average for the age group was 17.13. With age, depression leads to more suicides than alcohol/substance use disorders. The most developed country clusters 1-2 are the exception, where workingage people (15-49) commit nearly the same number of suicides as people aged over 70. One of the reasons is, presumably, a reaction to failures associated with one's career and personal life (personal failures), which, in terms of Henry and Short, differs from social failure, as it implies auto-aggression. Nikos Antonakakis and Alan Collins (2018) found that in high-income countries income increases are likely to lead to deteriorating mental health, while in middle-income countries income rises will rather affect mental health positively.

Suicide is most often associated with alcohol/substance use disorders (corr. 0.7 ) among men, and with depression among women (corr. 0.3). This is partly caused by the fact that women are generally less prone to alcohol and drug addiction than men (see Wilsnack et al., 2009). The highest rate of alcohol/substance use disorders was in Russia (5.9\% of the population), Estonia (5.48\%), the United States (5.47\%), Belarus and Ukraine (5.0\% each), with the world average of $2.3 \%$. The average suicide rate among men across the 136 countries is 15.5 per 100,000 people and is highest in Lithuania ( 58 per 100,000), Russia (56), Belarus (47), and Ukraine (41). The highest rates among women were in South Korea (15.4), India (14.7), Belgium (13.8), Switzerland (12.4), France (11.7), and Japan (11.4). Thus, among men, suicides occur most frequently in post-Soviet countries within clusters 2 and 3, and among women in developed countries from cluster 1 and in post-Soviet countries.

Countries with relatively high social inequality demonstrate a wide gap in male and female suicide rates, where male suicide rates are significantly higher than similar indicators in developed countries with low social inequality. However, in difficult social conditions the difference between male and female suicide rates is also low (Nigeria, Bangladesh). In the Netherlands, Norway, and Switzerland, the male suicide rate is almost twice as high as the female rate, but in Estonia, Georgia, Russia, and Panama it is over four times higher. 
On average, the male suicide rate is approximately 3 times higher than that of the female.

\section{The issue of "happiness" in BRICS countries}

The use of various "happiness" indicators has a long tradition, although economists have not been widely involved in its analysis, since they tend to believe that a growing per capita income has a favorable impact on the feeling of happiness (Easterlin, 1995). In particular, some academic papers refer to the rare case of Brazil: surveys showed that its citizens are happy despite quite modest income and social insecurity (Easterlin, 1995). Experimental studies have shown that it is not always so: happiness heavily depends not so much on absolute income growth, but more on that of relative growth, resulting from an individual's comparison of himself with other members of society. For example, Chinese citizens demonstrated decreasing happiness under high economic growth rates (Brockmann et al., 2009).

Popular in recent years, the "happiness" indicator (mentioned above) is a compound indicator consisting of indexes such as logarithmic GDP per capita, social connections (support by friends and relatives), healthy life expectancy, freedom of choice, charity during past 12 months, perceived corruption, the level of positive and negative emotions (average frequency of the feeling of happiness, joy, anxiety, fun, and anger, respectively), confidence in the national government, the state of democracy, the quality of services, the proportion of the poorest part of the population, i.e. an index reflecting the level of inequality, and level of interpersonal trust. It is a non-specialized index, but it covers many social, political, and psychological factors that influence life satisfaction. Thus, it is a kind of convention explaining why people in countries with stable social institutions and high income might or should be happy.

Thus, there is an important difference between the three variables: national homicide and suicide indicators are statistically observable and both result from the behavior of an individual and his or her reaction to life events. On the other hand, the "happiness" index is, in essence, an estimated indicator reflecting a certain normative hypothesis of its authors: the indicators of which (and the weight of which) should make people happy, with the same principle applied to all populations around the world. This is, undoubtedly, an exaggeration, as the "happiness formula" cannot be the same for the wide variety of countries, levels of development, cultural codes, citizen awareness of democracy and its actual state. In our opinion, it makes more sense for the developed countries. Therefore, we use the "happiness" index cautiously; the more the cluster is closer to the particular value system, the more reliable the "happiness" indicator is. The general hypothesis regarding the estimated "happiness" indicator could be that if it reflected emotional state, it would be in negative correlation with suicide. However, the estimated index also correlates positively with suicide rate in top country clusters $(-0.18$ coefficient $)$, where social institutions are developed and effective. Below we examine this problem in the BRICS countries.

The average "happiness" index for population around the world has remained roughly the same (5.4 points out of 10.0) over the last 12 years, whereas average 
well-being has been growing. The studies which referred to these statistics confirmed the paradox that emotional well-being, i.e. happiness, unlike satisfaction with life, is not closely connected with income (Kahneman and Deaton, 2010). These papers often underline that people evaluate their well-being based on relative indicators rather than absolute ones, through a comparison with the wellbeing of those around them. Thus, the socioeconomic situation and the mental health of citizens should be correlated. In this paragraph, we briefly review the connection between "happiness" indicators and the phenomenon of homicide and suicide in BRICS countries, whereas the problem as a whole deserves closer attention from scholars.

As we noted above, the "happiness" index is rather a target indicator than a survey-based indicator of the emotional attitude of people to their lives. For simplicity, we divided the survey-based "happiness" indicator by the "happiness" index in BRICS countries for 2010-2014 (Table 16). Countries, of course, differ significantly in the type and development of institutions, but when averaged, the differences are very significant in favor of Brazil, which after 2014 suffered a severe crisis, involving corruption, and the partial change of elites. We understand that the crisis in Brazil and the recession in Russia and South Africa should have affected both the estimated and the survey index. As for the rest, the question arises, if the calculated "happiness" index was understated for China and if it was overstated for Brazil — deviations from the ratio for the other three countries are somewhat high (15.3-16.0). The relationship between the two indicators of social anomie and the survey and calculated indicators of "happiness" in the BRICS countries cannot be simple — after all, our analysis shows an increasing relative suicide rate in developed countries. Here we bring up more issues than can be solved using the given statistics, so further research is needed. Such indicators should be analyzed with great attention though.

It should be noted that, in the context of the social and psychological situation in the BRICS countries, the contrast between "happiness" (both estimated and survey-based) and population loss caused by homicide and suicide remains (see Table 17). Brazil's citizens commit suicide relatively less frequently. But Brazil, South Africa and Russia, on the other hand, have high homicide rates, a sad but

Table 16

Comparison of population surveys on "happiness" in BRICS countries with the "happiness" index.

\begin{tabular}{|c|c|c|c|c|}
\hline \multirow[t]{2}{*}{ Country } & $\begin{array}{l}\text { "Happiness" } \\
\text { index, points } \\
\text { 2010-2012 } \\
\end{array}$ & $\begin{array}{l}\text { "Happiness" } \\
\text { index, points, } \\
2017\end{array}$ & \multirow{2}{*}{$\begin{array}{l}\text { "Happiness" } \\
\text { based on surveys, } \\
\%, 2010-2014^{\mathrm{b})} \\
\text { (b) }\end{array}$} & \multirow{2}{*}{$\begin{array}{l}\text { Indicator ratio } \\
\text { for 2010-2014 } \\
\text { (b) } / \text { (a) }\end{array}$} \\
\hline & (a) & & & \\
\hline Brazil & 6.85 & 6.64 & 92.0 & 13.4 \\
\hline Russia & 5.46 & 5.96 & 87.4 & 16.0 \\
\hline India & 4.77 & 4.32 & 73.3 & 15.4 \\
\hline China & 5.00 & 5.27 & 84.5 & 16.9 \\
\hline South Africa & 5.00 & 4.83 & 76.4 & 15.3 \\
\hline
\end{tabular}

a) On a scale from 1 to 10 points.

b) Percentage of people who responded with "very happy" or "mostly happy" to the question, "How happy are you?"

Sources: World Values Survey, World Happiness Report. 
Table 17

Average homicide and suicide rates in BRICS countries.

\begin{tabular}{llllll}
\hline \multirow{2}{*}{ Country } & \multicolumn{2}{l}{ Homicides per } & 100,000 people, & & \multicolumn{2}{l}{ Suicides per 100,000 people, } \\
\cline { 2 - 3 } \cline { 5 - 6 } & 2000 & 2017 & & 2000 & 2017 \\
\hline Brazil & 32.1 & 31 & & 6.3 & 6.1 \\
Russia & 34 & 14.8 & & 44.1 & 25.1 \\
India & 4.3 & 3 & & 19.7 & 15.6 \\
China & 2.6 & 1 & & 14.3 & 7.2 \\
South Africa & 60 & 28.6 & & 24.3 & 11.1 \\
\hline
\end{tabular}

Source: Institute for Health Metrics and Evaluation. (The data differ from Russian national statistics.)

not surprising trend probably largely explained by the degree of inequality as we demonstrated above. The low values of both indicators in India and China are impressive, although, given the large populations in these countries, their contribution to the total global loss of life remains conspicuous.

The development of the BRICS countries as regional leaders and the improvement of their social institutions influence the situation in neighboring countries. Therefore, the reduction of homicide and suicide rates in Russia, Brazil, and South Africa is not only an indicator of their internal state, not only a part of their transition to sustainable development, but also an example of improvement of their citizens life conditions. There are reasons to suppose that higher incomes in the countries within the group will not cause higher suicide rates. More extensive research is necessary to understand these processes better.

\section{The features of the problem under discussion in transitional economies and in Russia and its regions}

Countries in transition comprise a big important group with a very similar fate over the past 30 years, albeit with very different levels of development and degrees of success in their transformation. Our analysis would be incomplete without at least a brief description of the situation in Russia and other transitional economies. It should be noted that Russian demographers explore the problem of high mortality rates (see Vishnevsky, 2015, 2017; Kvasha et al., 2014; Andreev et al., 2016; Aminov, 2016), the issue of homicide and suicide in particular (along with road accidents, deficiencies in the healthcare system, etc.). However, we failed to find comprehensive sociological studies on homicide and suicide in transitional countries.

For Russia, where levels of inequality and levels of homicide and suicides remain relatively high compared with other countries, this topic is of high importance for social policy and assessing the state of society as a whole. An in-depth study of this problem is of particular importance for the demographic policy in the country, since the loss of population (especially men) for various reasons not related to the natural factors of disease and age is huge. International sources, however, provide figures about the level of suicides in Russia, which are higher than Russian ones (see Institute for Health Metrics and Evaluation, Fedstat). We use data from international sources in the correlation and regression analysis and international comparisons, but in this section we will apply the national data for a domestic regional perspective. 
Russia follows the same paradigm as other Eastern European countries: although the relative homicide and suicide rates are significantly higher than the region's average, trends are similar. Nevertheless, despite common culture and history, Eastern European countries and Russia are characterized by similar but differently-developing socioeconomic patterns and inequality models. In the Czech Republic, Slovakia, and Serbia, homicide and suicide rates decreased throughout the entire period; as noted in the article "The structure of social inequality in the modern world: measurement problems," (Grigoryev and Salmina, 2013), Eastern European countries and Russia are similar in terms of the average level of economic development and a significant degree of inequality, but some of these countries may adopt the north-central European social model.

The 1990s were a period of notable growth of homicide and suicide ratios in countries undergoing the transformation from a planned to market economy (Table 18). Anomie in a society, weak state and profound economic crisis were common factors for all. Notwithstanding this, individual countries' characteristics played a pivotal part; for instance there was less than 1 victim of an interpersonal violence per 100,000 people in Slovenia in 2017.

Table 18 provides an overview of the general behavior model for the two indicators during the period under review: the growth in both indicators in 1990 and 2000 (omitting the detailed analysis of the time model in this paper) and the subsequent decrease until 2017. In this case, we did not attempt to analyze sophisticated individual societal transformation models over more than a quarter of a century. We believe that civil conflicts, the scale of the economic crisis, and the degree of the weakening of the state determined differences in levels and trends.

We would notice that countries in transition, which joined the EU, demonstrate low homicide rates and rather high (but decreasing) suicide rates - quite a predictable dynamics for the period up to 2017. Some countries, especially those in the post-Soviet space are showing a great diversity of patterns. In particular, Armenia, Azerbaijan, and Georgia have shown rather modest initial suicide rates, which increased greatly during the $21^{\text {st }}$ century; also Latvia, Lithuania, and Estonia have high suicide rates. These patterns indicate stresses within the societies given all the differences in their socioeconomic situations.

It has been noted (Grigoryev and Pavlyushina, 2019) that social inequality in post-socialist countries increased during the transition in 1990s and then started decreasing slightly in the $21^{\text {st }}$ century. In our opinion, here we have the confirmation of the above-mentioned connection between inequality and homicide frequency. However we would not wish to simplify the complexity of a social interdependence in this area. Many other factors affected both tragic phenomena and mediated them. Obviously, this is a topic for further research.

Russia belongs to the $2^{\text {nd }}$ cluster of countries with its 25000 international dollars per capita. Although in Russia the murder rate per 100 thousand people is still higher than the average in the group of countries of 1-2 clusters (rather, our indicators are similar for cluster 4), it should also be noted that the number has been decreasing since 2000. A sharp increase in the suicide rate in our country occurred in 1990-2002 (see Fig. 2). A similar problem took place in many other countries that underwent a period of socio-economic transformation. Now it has fallen markedly, but still remains a serious problem. 


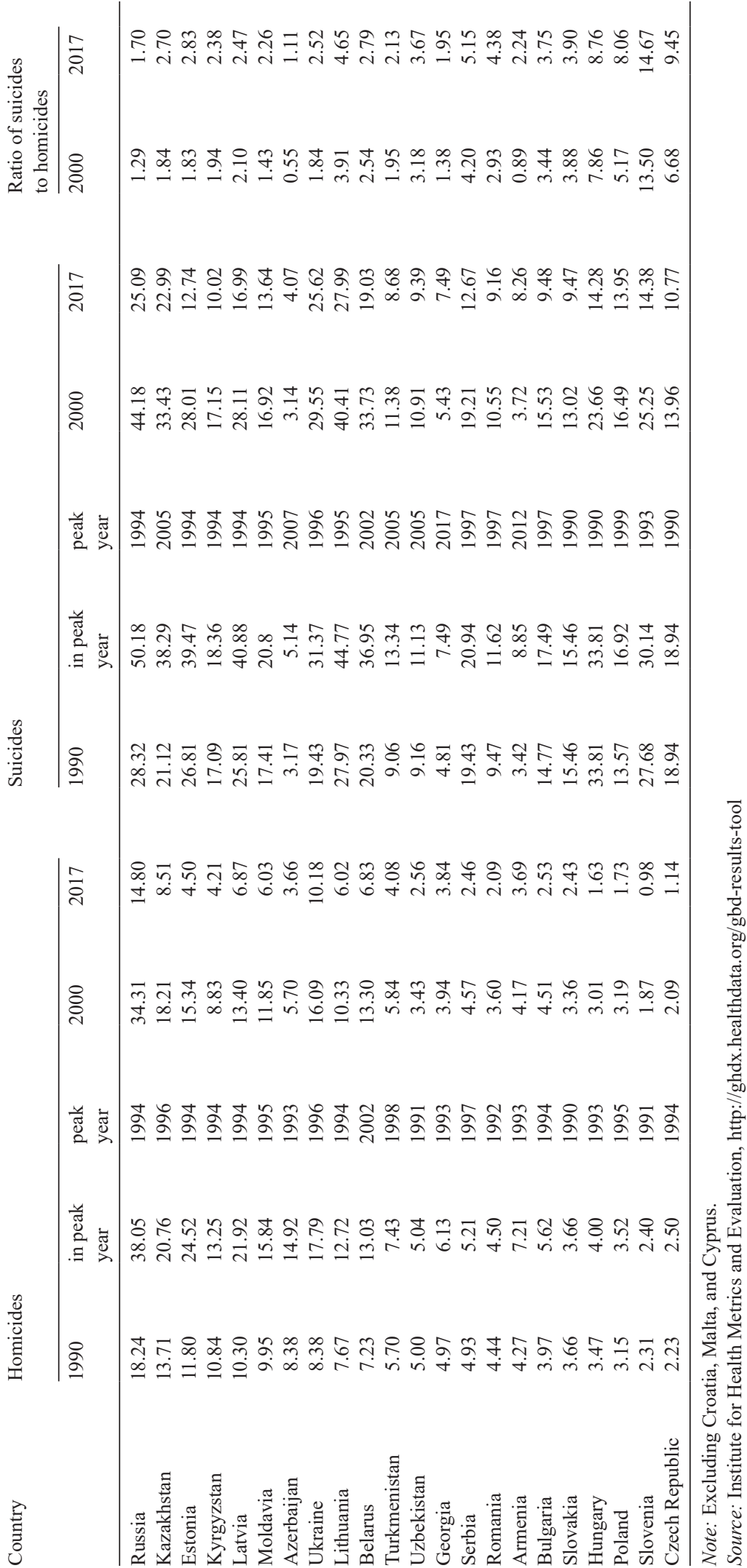






Fig. 3. Suicides and homicides per 100,000 people in Russia, 1990-2017.

Note: Here is the national count. The data provided by the Unified Interdepartmental Information and Statistical System (EMISS) differ from the data provided by the Institute for Health Metrics and Evaluation as shown in Table 18.

Source: Fedstat, https://fedstat.ru/indicator/31270

The weakening of the state (severe anomie of the 1990s), the impoverishment of a significant part of the population in the 1990s with the rapid and pervasive social differentiation, resulted in a "two-humped" leap in the dynamics of interpersonal violence (Fig. 3). Peaks showed up in 1994 and 2001, after that the indicators had been declining slowly but steadily, so in 2017 they reached a minimum over 27 years. It is difficult for us to give a forecast for the future, but we note that the level of the population losses in Russia is comparable with the population losses in Brazil and South Africa. The difference is that in these countries three-quarters of the losses account for murders whereas in Russia almost two-thirds are suicides.

Economic recovery and strengthening of the Russian state in 2000-2017 had a positive effect on reducing the intensity of the phenomenon of murders and suicides in Russia. Our calculations made it possible to test the hypothesis about the relationship between the level of development and the nature (intensity) of losses within the country by region. Previously, we established an important fact regarding the decrease in the intensity of homicides and suicides from 2000 to 2017 along the entire number of regions (ranked by GRP per capita). Economic growth in Russia in the 2000s was of different intensity before and after 2008, so the increase in per capita income went extremely unevenly over time. It is important to understand what happens to such difficult social problems in the conditions of a gradual normalization of social life (not widely felt prosperity but the absence of a sharp income drop until 2015). During the recession of 20152016 the dynamics of both indicators didn't change, although the ratio of 2017 indices to those of 2014 didn't shrink much.

Russian regions are far from being homogeneous in their level of development and production structure, which requires a systemic approach (see Grigoriev et al., 2008). From a practical point of view, it should be noted that during the period from 2000-2017, GRP for the group of highly developed regions (financial centers and oil producing regions) was approximately 140 points (with 100 as the national average), developed industrial regions - 80 points, moderately developed - 60, and less developed - 40 points (Grigoriev et al., 2008). These 
Table 19

Weighted average Human development index (HDI) and homicide and suicide rates in Russia by type of region, 2000 and 2017.

\begin{tabular}{|c|c|c|c|c|c|c|}
\hline \multirow[t]{2}{*}{ Region type } & \multirow{2}{*}{$\begin{array}{l}\text { HDI } \\
2017\end{array}$} & \multicolumn{2}{|c|}{$\begin{array}{l}\text { Homicides per } \\
100,000 \text { people }\end{array}$} & \multicolumn{2}{|c|}{$\begin{array}{l}\text { Suicides per } \\
100,000 \text { people } \\
\end{array}$} & \multirow{2}{*}{$\begin{array}{l}\begin{array}{l}\text { Share of } \\
\text { population, } \%\end{array} \\
2017\end{array}$} \\
\hline & & 2000 & 2017 & 2000 & 2017 & \\
\hline 1. Financial centers & 0.929 & 19.4 & 4.2 & 18.6 & 6.6 & 0.173 \\
\hline 2. Commodities exporters & 0.901 & 38.7 & 9.6 & 40.8 & 17.4 & 0.031 \\
\hline 3. Diversified & 0.888 & 24.6 & 5.2 & 37.3 & 9.9 & 0.157 \\
\hline 4. Manufacturing & 0.879 & 28.0 & 7.7 & 47.1 & 17.4 & 0.120 \\
\hline 5. Mining & 0.879 & 34.85 & 7.4 & 53.5 & 21.0 & 0.087 \\
\hline 6. Industrial-agro & 0.859 & 32.6 & 7.7 & 47.2 & 17.0 & 0.110 \\
\hline 7. Agro-industrial & 0.857 & 24.0 & 5.4 & 38.7 & 14.9 & 0.250 \\
\hline 8. Less developed commodities & 0.860 & 46.5 & 17.0 & 73.0 & 38.4 & 0.014 \\
\hline 9. Less developed agro & 0.829 & 37.68 & 4.0 & 39.48 & 6.5 & 0.056 \\
\hline
\end{tabular}

Note: Weighted average national statistics differ from Fedstat's summary data.

Sources: Golyashev and Grigoryev (2014); Fedstat, https://fedstat.ru/indicator/31270

ratios are relatively stable despite the upward movement for some regions and the general income growth; significant gaps between regional groups can be seen from the Human development index.

We can practically rely on the international comparisons above to formulate a hypothesis regarding the expected indicator rates in regions given different levels of development. Of course, Russia's regions are not countries with separate histories and institutions. However, there cannot be flat regional distributions of tragedies under discussion. We could assume that the most developed regions should demonstrate relatively low homicide rates, but it is much more difficult to formulate a hypothesis with respect to suicide rates. The actual state of affairs is shown in Table 19. As seen from the table, homicide rates declined to 14.8 per 100,000 people by 2017 , and are relatively low in financial centers and diversified, developed regions. The highest rates are in Siberia and in the Far East — marked by the domination of commodity producing sectors. The reduction of suicide frequency is also quite conspicuous, although it is still high at the country's current stage of development and human development index. Certain doubts remain in Russia as to the quality of statistical data. In cross-country comparisons below, for the sake of comparability, we used statistics from an international source.

The reduction of the relative homicide and suicide parameters by region from 2000 to 2017 reflects both the general trend and the specific aspects of the socioeconomic situation in different types of regions (see Table 19). The reduction of population loss by two parameters taken together from 38.0 to 10.8 per 100,000 people in financial and economic centers (Moscow, St. Petersburg, Moscow Region) and at similar rates in diversified developed regions (both groups having the highest HDI) was caused by (in our opinion) social factors and could be called a huge success. In these most developed regions, these two parameters are similar to developed countries.

The most impressive achievement in the reduction of individual tragedies happened in the most developed and diversified regions. That is quite logical, since they provide the population with opportunities for personal fulfillment. Homicide, as an indirect repercussion of inequality, is supposed to be restricted by the legal and law enforcement system. Suicides in society, caused by despair, 
personal "dead ends", or personal career or business failures cannot be avoided completely. However, diversified cities (regions) provide citizens with more choice, opportunities for a new start and self-realization. This may seem paradoxical, given the fact that in the well-off countries in clusters $1-2$, the suicide rate is higher than in other clusters. It may be explained in a more detailed analysis of the accompanying factors, social environment, and the regional specifics for other countries - the subject for further research. Russia has one of the world's highest national suicide rates, and it is quite difficult to say whether it will decline along with economic progress to the level of developed countries, or if it will fluctuate at roughly the same level.

Anyhow, the two phenomena require close attention and research, both in general, regarding the motives for respective dynamics, and the circumstances that cause it (particularly the trend). Such research should have a regional dimension and probably a socio-demographic perspective: age, gender, occupation, etc. However, the overall situation remains difficult. We believe that the rates and trends for these indicators by type of region (rather than for the country as a whole) provide more informative data for researchers into social processes.

\section{Discussion of results. Why has the world community not set the goal of reducing homicide and suicide rates?}

Unfortunately, the phenomenon of homicide and suicide is especially common in a number of regions around the world and in Russia. However, both homicide and suicide rates are significantly lower in financial centers and diversified developed regions. This contrast looks even more dramatic within a single country because regions with different levels of development are neighbors in a vast territory. Income and human development indices are higher in states capitals and developed diversified regions; it is highly close to the world's country clusters $1-2$, in which we can see a high suicide rate but a low homicide rate. In the Sustainable Development Goals Agreement of UN (2015) the world community raised the question of improving the standards of living and reducing inequality. Surprisingly, SDG was shy to mention (or set a goal and an indicator regarding) such tragic aspects of life in modern society as homicide and suicide (the latter appeared only as an indicator of mental health). Given Russia's difficult demographic situation, homicide and suicide should be considered carefully in social policies. They are the result and the source of a critical socio-psychological condition in many strata within the society and in particular by the regions. In this respect, ensuring prosperity is of paramount importance: a reduction in violence and despair within society could be attributed to reduced homicide and suicide rates.

Our goal was to study homicide and suicide rates dynamics in various countries around the world and to find out whether psychosocial factors prove the presence of elements of anomie within society. We can observe that this process is accompanied by growing isolation, loneliness, and despair and with more intensive perceived "personal failures" which lead to a relative increase in suicide rates. Psychosocial factors, such as alcohol/substance use problems, anxiety disorders and depression, are not reliable indicators of an adverse or some other state of a society. 
Based on the results of the study, we came to the following important conclusions.

- The cluster analysis by GDP (PPP) per capita allows for more accurate conclusions than analyzing the whole sample, and identifies specific features of social processes.

- The dispersion of homicide and suicide rates across the main body of countries is stable over time (2000-2017). However, on the whole, the indicators reviewed reflect social and cultural aspects of the countries and therefore they change slowly. We believe that, depending on the level of development, historical and cultural specifics, countries are characterized by various specific "sets" of social diseases.

- The differentiation of Islamic countries into a separate group let us come to more accurate results as this religion has a substantial impact on all social spheres. This may be relevant for UN sustainable development programs.

- Predictably, the relative frequency of homicide by country was found to be an indicator attributable to social factors, namely income inequality. In our opinion, this can be considered a stylized fact applicable to a vast majority of countries and periods.

- The analysis did not prove any correlation between homicide and suicide rates, but their general trends are opposite (if countries are sorted by GDP per capita): the peak homicide rate occurs in cluster 4 and the peak suicide rate occurs in clusters 1-2. The sharp drop in the relative homicide frequency in cluster 1 (to 1.45 per 100,000 ) may point to the quantified threshold that tells postindustrial countries apart from those at earlier development stages.

- In our opinion, individual indicator rates reflect the specifics of each country or country group, which indicates the need to examine the problem of tradition, cultural codes and religious factors. The combination of the rates of the two indicators is apparently also specific to each country (e.g. opposite differences in rates between Brazil and Russia). However, the trends in the indicators reflect social processes and social anomie (countries undergoing transformation in our age).

- For countries in transition, difficult periods of economic crises and changes created the environment for the growth in individual tragedies. The reduction in homicide and suicide rates indicates the success of society's post-transitional stabilization.

We are far from reaching assumptions about solutions to social aspects of the homicide and suicide phenomena. We would like to emphasize the insufficient amount of research on this topic. To obtain the best understanding of the socioeconomic context of suicide and its correlation with homicide and the level of "happiness", future studies should pay particular attention to developed and developing countries (particularly the BRICS countries). Post-Soviet countries are important objects of research as the closest to Russia in terms of culture and similar social anomie in 1990-2018. We believe that study of this phenomenon could become part of the research on the transition from an industrial to a postindustrial society, and the role of cultural codes in the life of modern society. It would be rational and ethical to include this phenomenon in the process of ensuring the sustainable development of the world, which is incompatible with war and crime and with large-scale suicide and interpersonal violence. Individual tragedies matter! 


\section{References}

Aminov, I. (2016). Suicide in Russia. Demoscope Weekly, No. 705-706 (in Russian).

Andreev, E., Kvasha, E., \& Kharkova, T. (2016). Mortality in Moscow and other megacities of the world: Similarities and differences. Demographic Review, English selection 2016, 79-115. https://doi.org/10.17323/demreview.v3i5.7312

Antonakakis, N., \& Collins, A. (2018). A suicidal Kuznets curve? Economics Letters, 166, 90-93 https://doi.org/10.1016/j.econlet.2018.02.013

Boskoff, A. (1982). Social failure in modern society: A reformulation and a tentative theoretical framework. Sociological Inquiry, 52 (2), 89-105. https://doi.org/10.1111/j.1475-682x.1982. tb01241.x

Brockmann, H., Delhey, J., Welzel, C., \& Yuan, H. (2009). The China puzzle: Falling happiness in a rising economy. Journal of Happiness Studies, 10 (4), 387-405. https://doi.org/10.1007/ s10902-008-9095-4

Collins, A., Cox, A., Kizys, R., Haynes, F., Machin, S., \& Sampson B. (2019). Suicide, sentiment and crisis. The Social Science Journal. https://doi.org/10.1016/j.soscij.2019.04.001

Corzine, J. (2011). The homicide theories. The Homicide Studies, 15 (4), 315-318. https://doi. org/10.1177/1088767911424540

Durkheim, E. (1994). Suicide: A study in sociology. Moscow: Mysl (in Russian).

Easterlin, R. A. (1995). Will raising the incomes of all increase the happiness of all? Journal of Economic Behavior and Organization, 27 (1), 35-47. https://doi.org/10.1016/01672681(95)00003-b

Golyashev, A. V., \& Grigoryev, L. M. (2014). Types of Russian regions: Sustainability and shifts in 2003-2013. Moscow: Analytical Center for the Government of Russian Federation (in Russian).

Grigoriev, L., Zubarevich, N., \& Urozhaeva, Y. (2008). Scylla and Charybdis of regional policy. Voprosy Ekonomiki, 2, 83-98 (in Russian). https://doi.org/10.32609/0042-8736-2008-2-83-98

Grigoryev, L. M., \& Pavlyushina, V. A. (2018a). Inter-country inequality as a dynamic process and the problem of post-industrial development. Voprosy Ekonomiki, 7, 5-29 (in Russian). https:// doi.org/10.32609/0042-8736-2018-7-5-29

Grigoryev, L. M., \& Pavlyushina, V. A. (2018b). Social inequality in the world: Trends during 2000-2016. Voprosy Ekonomiki, 10, 29-52 (in Russian). https://doi.org/10.32609/0042-87362018-10-29-52

Grigoryev, L. M., \& Pavlyushina, V. A. (2019). Relative social inequality in the world: Rigidity against the economic growth, 1992-2016. Russian Journal of Economics, 5 (1), 46-66. https:// doi.org/10.32609/j.ruje.5.35485

Grigoryev, L. M., \& Salmina, A. A. (2013). "Structure" of inequality in the modern world: Problems of measurement. Sociological Journal, 3, 5-21 (in Russian).

Helliwell, J., Layard, R., \& Sachs, J. (2016). World happiness report 2016, update (Vol. I). New York: Sustainable Development Solutions Network.

Henry, A. F., \& Short, J. F. (1954). Suicide and homicide: Some economic, sociological and psychological aspects of aggression. Glencoe, IL: Free Press.

Hufford, M. R. (2001). Alcohol and suicidal behavior. Clinical Psychology Review, 21 (5), $797-$ 811. https://doi.org/10.1016/s0272-7358(00)00070-2

Kahneman, D., \& Deaton, A. (2010). High income improves evaluation of life but not emotional well-being. Proceedings of the National Academy of Sciences, 107 (38), 16489-16493. https:// doi.org/10.1073/pnas.1011492107

Kvasha, E., Kharkova, T., \& Yumaguzin, V. (2014). Mortality from external causes in Russia over half a century. Demographic Review, English selection 2014, 85-108. https://doi.org/10.17323/ demreview.v1i5.3174

Lester, D. (1986). Suicide, homicide and the quality of life: An archival study. Suicide and LifeThreatening Behavior, 16 (3), 389-392. https://doi.org/10.1111/j.1943-278x.1986.tb01020.x

Sherman, R. M., D’Orio, B., Rhodes, M. N., Gantt, S., \& Kaslow, N. J. (2014). Racial/ethnic, spiritual/religious, and sexual orientation influences on suicidal behaviors. In M. K. Nock (Ed.), The Oxford handbook of suicide and self-injury (pp. 265-285). New York: Oxford University Press. 
Smith, M., \& Zahn, M. (1999). Homicide. A sourcebook of social research. Sage Publications. UN (2015). Transforming our world: The 2030 agenda for sustainable development. New York.

Unnithan, N. P. \& Whitt, H. P. (1992). Inequality, economic development and lethal violence: A cross-national study of homicide and suicide. International Journal of Comparative Sociology, 33, 182-196.

Unnithan, N. P., Whitt, H. P., Hufl-Corzine, L., \& Corzine, J. (1994). The currents of lethal violence: An integrated model of suicide and homicide. Albany: SUNY Press.

Van Orden, K. A., Witte, T. K., Cukrowicz, K. C., Braithwaite, S. R., Selby, E. A., \& Joiner Jr., T. E. (2010). The interpersonal theory of suicide. Psychological Review, 117 (2), 575-600. https:// doi.org/10.1037/a0018697

Vishnevsky, A. G. (2015). Mortality in Russia: The second epidemiologic revolution that never was. Demographic Review, English selection 2015, 4-33. https://oi.org/10.17323/demreview. v2i5.5581

Vishnevsky, A. G. (2017). Deaths from external factors in Russia from the middle of XX century. Moscow: Higher School of Economics (in Russian).

Wilsnack, R. W., Wilsnack, S. C., Kristjanson, A. F., Vogeltanz-Holm, N. D., \& Gmel, G. (2009). Gender and alcohol consumption: Patterns from the multinational GENACIS project. Addiction, 104 (9), 1487-1500. https://doi.org/10.1111/j.1360-0443.2009.02696.x

Yang, B. (1992). The economy and suicide: A time-series study of the U.S.A. American Journal of Economics and Sociology, 51 (1), 87-99. https://doi.org/10.1111/j.1536-7150.1992.tb02512.x 